\title{
2015 James Ewing Lecture: The 75-Year History of the Society of Surgical Oncology-Part II: The Transitional Years (1966-1990)
}

\author{
Charles M. Balch, $\mathrm{MD}^{1}$, Daniel G. Coit, $\mathrm{MD}^{2}$, and Russell S. Berman, $\mathrm{MD}^{3}$ \\ ${ }^{1}$ Department of Surgery, University of Texas Southwestern Medical Center, Dallas, TX; ${ }^{2}$ Memorial Sloan-Kettering \\ Cancer Center, New York, NY; ${ }^{3}$ Department of Surgery, New York University School of Medicine, New York, NY
}

The Society of Surgical Oncology (SSO), originally a multidisciplinary alumni organization for Memorial Hospital faculty and trainees (itself an important part of surgical oncology history), evolved into a national and then a global society primarily for surgeons treating cancer. We have identified 11 historical highlights, although many more could have been included (Table 1). Photos of SSO presidents during this era are shown in Fig. 1.

During this period (1965-1990), the SSO (founded as the James Ewing Society) emerged from a smaller Memorial Sloan-Kettering Cancer Center (MSKCC) alumni organization into a major national professional organization representing the broader interests of surgical oncologists wherever they trained. This also was an important period for defining the additional training necessary for surgical oncology to be characterized as a specialty in which oncologists would perform complex cancer operations. Indeed, the presidential leadership made great strides in defining the roles and responsibilities of a surgical oncologist. The curriculum of surgical oncology fellowship training was created, and the Society began the formal process of approving training programs throughout the United States (Table 2).

\section{THE FIRST PRESIDENTIAL ADDRESS OF THE JAMES EWING SOCIETY}

As the James Ewing Society grew in size and national stature during the 1960s, the Executive Council persuaded

(C) Society of Surgical Oncology 2015

First Received: 31 August 2015;

Published Online: 13 October 2015

C. M. Balch, MD

e-mail: charles.balch@utsouthwestern.edu1
Dr. Glenn Leak to give the first presidential address (Fig. 2). This was published in the journal Cancer in 1966, our first published Presidential Address. ${ }^{1}$

Dr. Leak cited advances in cancer treatments: methotrexate for choriocarcinomas, cobalt irradiation, Pap smears, and smoking cessation. ${ }^{1} \mathrm{He}$ was the first to present publicly his vision for the Society when he stated, "Some of us have learned that cancer was treated quite well in many places west of First Avenue." He further stated, "Our aim [of the Ewing Society] has changed to unite in membership those people interested in cancer." He concluded, "I doubt whether a president 50 years from now will ever bother to read these words...I hope and pray that 50 years from now, there will be no need for this Society because one of its members will have discovered the cause and another the cure of cancer." 1

\section{JAMES EWING SOCIETY RENAMED AS THE SOCIETY OF SURGICAL ONCOLOGY}

In 1975, the James Ewing Society was renamed as the SSO. An event this significant did not occur spontaneously but evolved after many often contentious discussions during several years. For instance, Dr. Sam Wilkins in his 1969 Presidential Address stated, "Some have voiced the opinion that our Society can never reach its greatest potential bearing the name of a single man... I do not believe that so long as we retain a man's name can we hope to interest other related societies in coming together. While I am not yet prepared to recommend changing the name of the Society, I do feel the matter should be given serious consideration as to what it might mean to the future of the Society and what it might accomplish if its name were less personal and more connotative of our purpose and scope...The James Ewing Society should in deed and in truth be a national cancer society in the fullest sense, 
TABLE 111 Seminal events in Society of Surgical Oncology (SSO) history

1940: Formation of the James Ewing Society in New York City 1948: First Annual Cancer Symposium of the James Ewing Society 1966: First Presidential Address by Dr Glenn H. Leak 1975: James Ewing Society renamed the Society of Surgical Oncology

1983: First surgical oncology fellowship training program approved

1994: Launch of the SSO journal Annals of Surgical Oncology

2003: First Breast Oncology Fellowship training program approved

2010: First "Best of SSO" presented by SMeO in Cancun

2011: First Fellows Institute program in Cincinnati Ohio

2011: American Board of Surgery-approved Surgical Oncology subspecialty certification

2012: SSO administration move to self-management

regardless of name. I believe we have a unique opportunity, a great challenge, and a serious responsibility to develop into such an organization." 2

One significant influence on the change in name came from a group of academic surgeons interested in forming an academic surgical oncology society. As Walter Lawrence stated later, "At a time [circa 1974-1975] when some academic surgeons [primarily Donald Morton and Tapas Das Gupta] were suggesting the formation of an academic surgical oncology society, it appeared that the transformation of this well-established oncology society, with strong surgical oncology input, would be a better solution to this need for a national subspecialty organization. The field of surgical oncology, poorly defined as it was at that time, could hardly undergo the further confusion of having two separate organizations representing it." ${ }^{3}$ In his James Ewing Lecture in 1990, Dr. Lawrence recalled this event, "There was considerable controversy in the James Ewing Society over the name change; however, the major argument against it was the potentially negative impact on the memory of the beloved Dr. James Ewing, a true hero of all the membership as well as the oncology community of the day. Many of us felt that the creation of an entirely new and separate national surgical oncology society, rather than merely changing the name of this society, would seriously threaten the future of the James Ewing Society by leading to a loss of valuable surgical members, while a name change would give this society an expanded role and purpose." 4

In the run-up to the James Ewing Society meeting in March 1975, President Ed Scanlon made a proposal to the Commission on Cancer of the American College of Surgeons that surgical oncology should be formally designated as a specialty. ${ }^{5}$ The minutes of the Commission on Cancer Executive Council on 12 January 1975 reflected this proposal: "Dr. Scanlon stated there had been much activity within the past 2 years by a number of surgeons directed toward bringing about recognition of surgical oncology as a definite surgical specialty. This issue has come to a head as a result of acceptability of the designations of medical oncologist, radiation oncologist, gynecological oncologist, pediatric oncologist, etc. In an effort to promote the recognition of surgical oncology, the James Ewing Society was to consider at its next meeting a change in its name to the SSO. A resolution had been prepared for presentation at the meeting. It now seemed important that this (Commission on Cancer) Executive Committee prepare a resolution to be presented to the (American College of Surgeons) Board of regents indicating approval of the designation 'surgical oncologist'."

A resolution was then forwarded to the Regents, which was approved on 7 February 1975 as follows: "Resolved, that the American College of Surgeons continues to support standards of excellence for surgeons involved in cancer education, research, diagnosis, and treatment, and that these are competent to act as members of the multidisciplinary cancer team as surgical oncologists."

In March 1975, President Edward Scanlon presided over the annual meeting of the James Ewing Society in New Orleans, where the discussions about the Society's name change culminated in what was described as "an emotional debate." ${ }^{6}$ Dr. Scanlon's Presidential Address set the stage for this debate. He said, "Clearly, the time has arrived for identifying the surgical oncologist...If the time has arrived, then some organization will be needed to represent surgical oncology. It seems so logical and so natural the James Ewing Society should be that organization. A proposed amendment is before you to effect this change... This will be an important decision." 6

Among several hundred members present, those who attended described the "vigorous debate" and "tumultuous discussions" about the proposed name change to the SSO. The impasse was broken by the strong supportive comments of Harvey Baker and by Murray Copeland, ${ }^{1}$ who was previously a vice president and Executive Council member of the James Ewing Society ${ }^{4,8}$ (Fig. 3). Dr. Copeland committed to the promise that the organization would continue to be true to the memory and inspiration of Dr. Ewing despite the name change. ${ }^{4}$ In addition, a newly created fund-raising entity associated with the SSO would bear the name of the James Ewing Foundation.

Looking back, President Blake Cady in 1989 described "the angst and turmoil that culminated in the 1975 annual meeting... when the executive committee recommended and the membership approved the name change to the

\footnotetext{
${ }^{1}$ Murray Copeland was the uncle of SSO past President Dr. Edward (Ted) Copeland.
} 

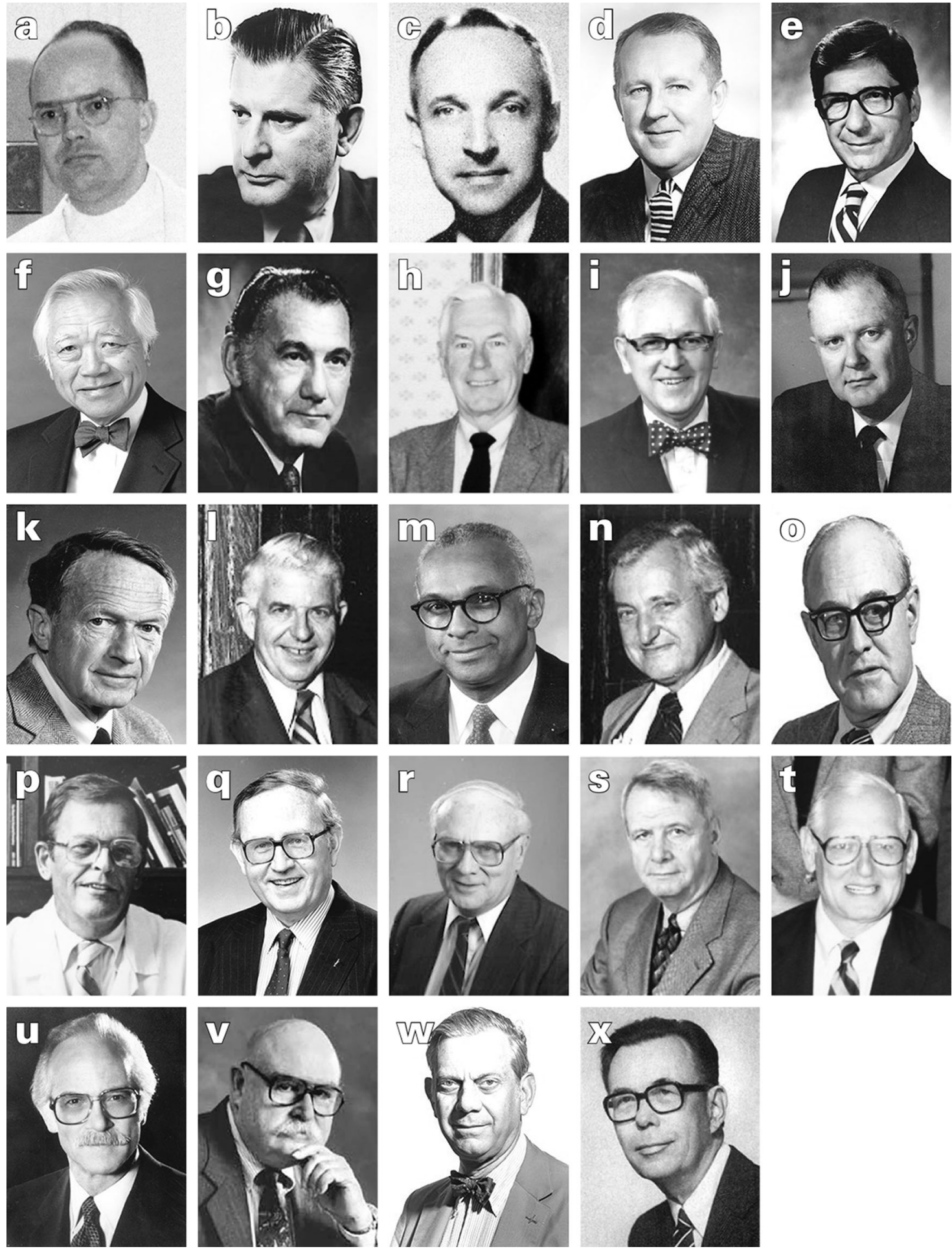

FIG. 1 Presidents of the Society of Surgical Oncology 1966-1990. a Glenn H. Leak, MD, 1965-1966. b Theodore R. Miller, MD, 19671968. c Sam A. Wilkins, Jr., MD, 1968-1969. d Guy F. Robbins, MD, 1969-1970. e Arthur G. James, MD, 1970-1971. f Stuart H. Q. Quan, MD, 1971-1972. g Arthur I. Holleb, MD, 1972-1973. h Robert J. Schweitzer, MD, 1973-1974. i Edward F. Scanlon, MD, 1974-1975. j Lewis W. Guiss, MD, 1975-1976. k William R. Nelson, MD, 19761977. I Harvey W. Baker, MD, 1977-1978. m LaSalle D. Leffall, Jr.,
MD, 1978-1979. n Walter Lawrence, Jr., MD, 1979-1980. o Condict Moore, MD, 1980-1981. p Jerome J. DeCosse, MD, 1981-1982. q Gerald P. Murphy, MD, 1982-1983. r Robert J. McKenna, Sr., MD, 1983-1984. s Hiram C. Polk, Jr., MD, 1984-1985. t Victor D. Dembrow, MD, 1985-1986. u Robert V. P. Hutter, MD, 1986-1987. v J. Bradley Aust, MD, 1987-1988. w Blake Cady, MD, 1988-1989. x Benjamin F. Rush, Jr., MD, 1989-1990. Not shown: Theodore Winship, MD, 1966-1967 
TABLE 2 Original criteria for evaluating a surgical oncology training program as published in 1979 and $1981^{11,12}$

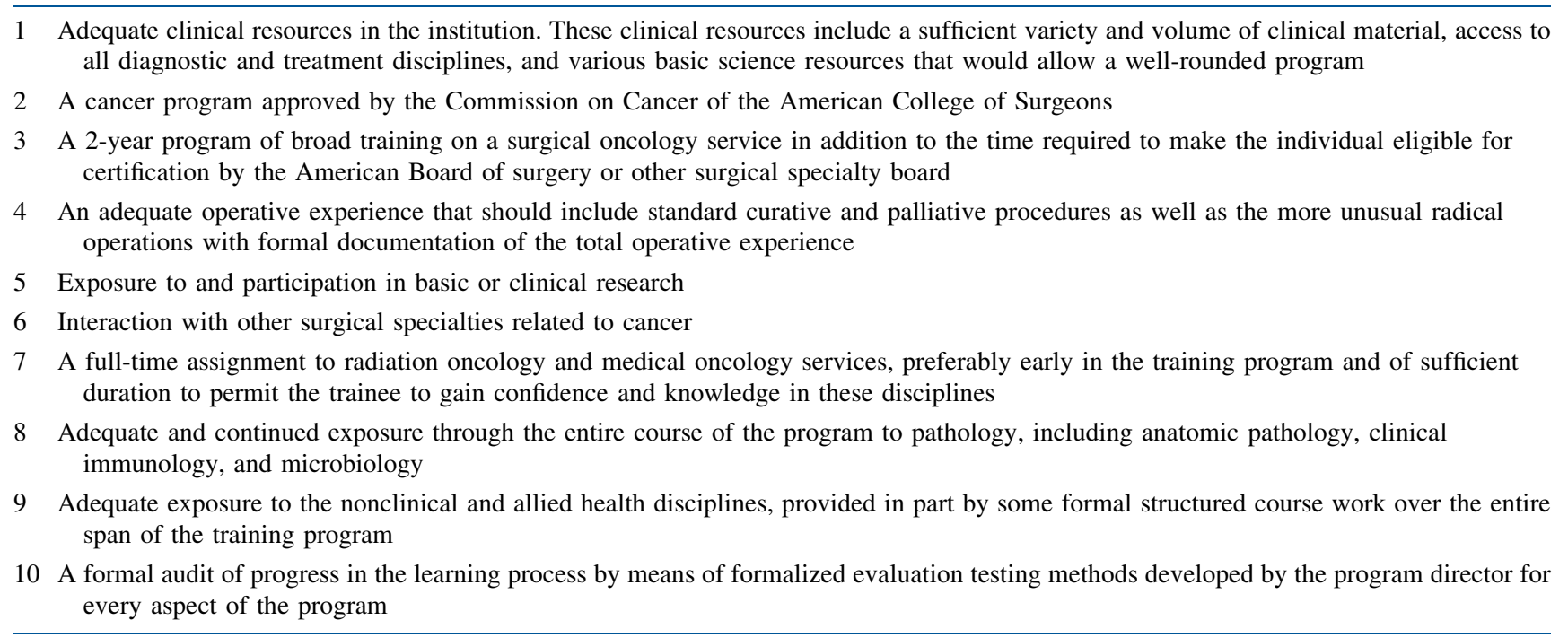

\title{
First Presidential Address of the James Ewing Society
}

\author{
JAMES EWING SOCIETY, 1940-1966 \\ Presidential Address
}

\begin{abstract}
T $T$ IS WITH a GREAT deAl OF PLEASURe That I welcome you back to New York for the nineteenth annual scientific session of the James Ewing Society. It will be very difficult for our hospitality to match that which we received in Houston last year but we will certainly try. For the first time in New York we are attempting to have a program and hospitality room for our ladies and I hope they enjoy it to the utmost. I want to thank all the

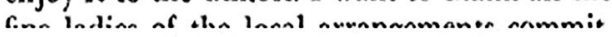

2. To associate in membership all those who received their training in cancer at Memorial Hospital.

Today, 18 years later, I do not feel that there is any question that the first purpose, of furthering the knowledge of cancer, still holds true. In talking to my colleagues in this society, I believe we have expanded this purpose to include quality-care of the cancer patient in the United States and abroad

FIG. 2 First Presidential Address of the James Ewing Society by Dr. Glenn H. Leak. Source: Cancer 19:1475, 1966

SSO." He said, "The prolonged prior debate and discussion, not all of it supportive needless to say, demonstrated the deliberate attempt of the farsighted leadership at that time to expand our influence broadly and project us onto the national and even international scene. Ed Scanlon, the president at that time, really put this change together as a response to contrary internal pressures, but other key players who supported his efforts were Don Morton, Murray Copeland, Harvey Baker, Walt Lawrence, and Bill Macomb... The membership approved the name change." 7
This bold move was not only a change in name but a new direction for the Society as a national organization of all surgical oncologists regardless where they trained or practiced. As stated by President Blake Cady, "Concerted and deliberate efforts were made to encourage basic and clinical science in our programs and to encourage debate in our meetings to make ourselves acceptable to the larger community, particularly the academic community."7

In 1979, Walter Lawrence wrote an editorial stating, "Surgical oncology is new, and still poorly defined. I am 
FIG. 3 Leaders in transformation of the James Ewing Society to become the Society of Surgical Oncology. a Edward Scanlon. b Left to right Murray Copeland, Harvey Baker, and Walter Lawrence. Photo courtesy of Dr Walter Lawrence
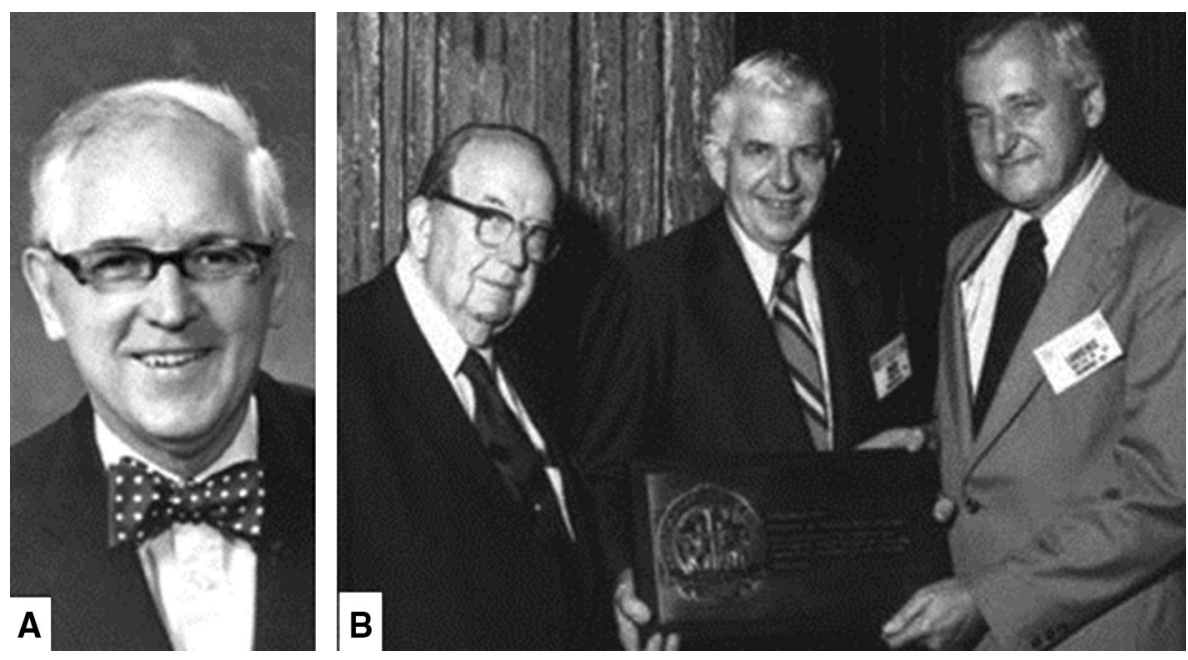

convinced, however, that it can and will make a contribution to the surgical care of the cancer patient in our nation... A major recent step in this process of (specialty) identification was the transformation of the James Ewing Society...into a new society, the SSO. With this change in name of the organization there were corresponding modifications in the objectives of the society and the membership requirements." 8

Five years after approval of the designation as the SSO, then President Walter Lawrence summarized the impact of the name change as follows: "The change in the name of our Society to the SSO 5 years ago did cause some consternation on the part of many...Nevertheless, the time had come for surgeons primarily concerned with cancer to work together within some organization to refine and expand the role of surgical oncologist...The surgeons among us who were committed to oncology clearly needed an organizational vehicle to fulfill our responsibilities as surgeons and to oncology as a whole,... and despite some expected criticisms, the transition to the SSO has been accomplished...It is my belief that the growth of the discipline of oncology within general surgery will never reach its full potential without the enthusiastic involvement of the educational system within our universities."

\section{THE BEGINNING OF SSO-APPROVED FELLOWSHIP TRAINING PROGRAMS}

Before describing the training of a surgical oncologist, the uniqueness of the specialty had to be defined. Many surgical oncology leaders participated in this process (see Sidebar for quotes from past presidents).

Although the major free-standing cancer centers had long-standing fellowship training programs, there was a dearth of post-residency surgical oncology training programs in academic medical centers. ${ }^{9}$ Among the early champions for expanding the number of surgical oncology training programs was Robert Schweitzer, whose 1974 James Ewing Presidential Address concluded: "It is essential that medical educators continue to recognize the importance of the surgical oncologist and establish training programs that will not only stimulate individuals to enter this field, but will enable them to keep abreast of the changing scene as related to surgery, radiation, and medical oncology... and allow the surgeon to continue to make significant and meaningful contributions in the multidisciplinary approach to cancer control." 10

During the period 1974-1978, the SSO took the leadership role of formally certifying surgical oncology training programs. Formal criteria for training surgical oncologists were established. The seminal event of defining surgical oncology training guidelines was formalized in 1978, when SSO leaders, together with representatives from the National Cancer Institute, held an important workshop on surgical oncology training. ${ }^{11,12}$ This workshop was led by Robert Schweitzer together with Ed Scanlon, Walter Lawrence, and LaSalle Leffall, Jr., all of whom were SSO presidents during that era (Fig. 4). The outcome of this 1978 meeting was a definition for the term "surgical oncologist" and a training curriculum that led directly to the SSO guidelines for approving surgical oncology fellowships. ${ }^{11-13}$ As summarized by Dr Walter Lawrence, "The surgical oncologist... is the well-qualified general surgeon who has obtained additional training and experience in the cancer field and then devotes his professional work almost solely to this activity." 8

The original criteria (Table 2) for approving surgical oncology fellowship training programs was used from 1978 until 2014, when the Accreditation Council for Graduate Medical Education (ACGME) began the process of reviewing surgical oncology programs. The first site visits for fellowship training programs approved in 1983 were the 

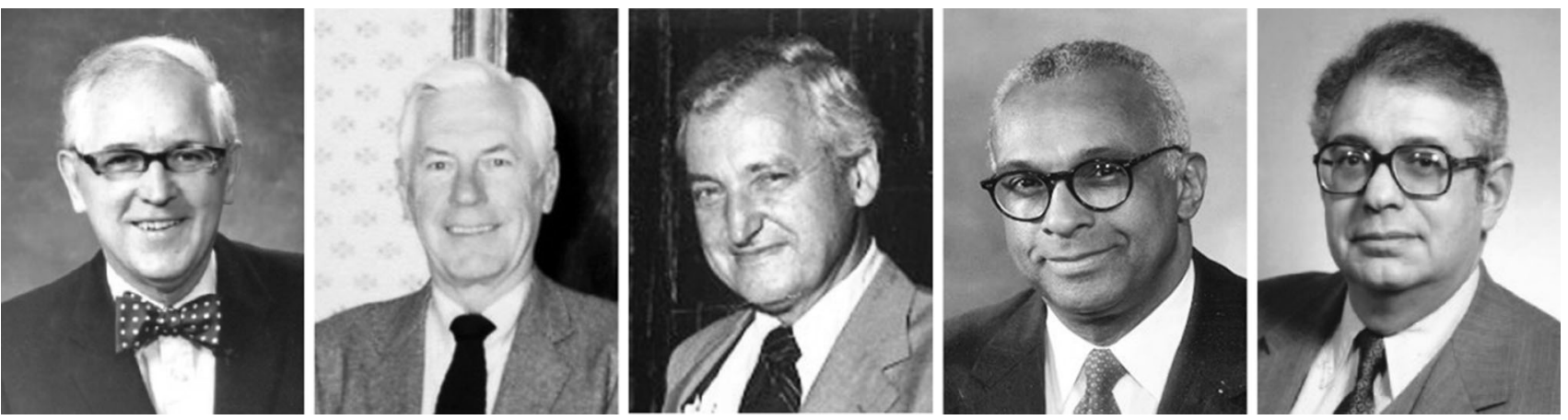

FIG. 4 Leaders in development of the SSO-certified fellowship training programs. Left to right Edward Scanlon, Robert Schweitzer, Walter Lawrence, LeSalle Leffall, and Bernard Gardner

Memorial Sloan-Kettering Cancer Center, the Roswell Park Cancer Institute, and Ohio State University. By 1989, there were nine approved programs. Great credit goes to the leadership of Robert Schweitzer and Bernard Gardner as the first SSO Training Committee chairs, both of whom later became SSO presidents.

By 1986, 47 university-based departments of surgery had designated divisions of surgical oncology, which comprised only $38 \%$ of the all the Surgery Departments at that time. ${ }^{2,14}$ Most of the surgical oncology faculty in these 47 institutions provided cancer education and mentoring to graduate and undergraduate trainees in surgery, but only 12 departments provided post-residency training in clinical surgical oncology. ${ }^{14}$ Clearly, the organizational concept of having a surgical oncology division or section had developed some momentum during the previous two decades, albeit slowly.

\section{8-1990: "IS SURGICAL ONCOLOGY WITHERING?"}

President Blake Cady in his 1989 Presidential Address described the SSO at a crossroads, which he said, "in many ways is the result of our success, growth, and increasing stature. ${ }^{77} \mathrm{He}$ then made a prescient statement that "The American Board of Surgery will turn down our request for specialty designation, but this provides an opportunity to analyze our future directions and exert more control of our destiny." 7

However, in the late 1980s, the SSO had lost some of its momentum. Both active membership and meeting attendance were declining. There was no growth in fellowship programs. The 1989 budget was in deficit, and the Society

\footnotetext{
${ }^{2}$ In contrast, most of these 124 academic medical centers had designated divisions of medical oncology (95\%), radiation oncology (94\%), pediatric oncology (76\%), and gynecologic oncology $(79 \%)$.
}

had a negative cash flow, even while management fees were increasing. Presidents Blake Cady, Benjamin Rush, and Alfred Ketcham saw the need to engage the leadership in a call to action (Fig. 1).

Indeed, President Benjamin Rush actually opened his presidential address in 1990 with the question: "Is surgical oncology withering?" He went on to say, "One can find evidence that this may be so...The American Board of Surgery has denied a certificate of added competency in surgical oncology. There was fragmentation of cancer care, especially for head and neck and GI cancers. The membership of the society had plateaued, and younger surgeons were not joining." ${ }^{15}$ As described by Dr. Rush, "We had managed to construct membership criteria that excludes individuals who consider themselves surgical oncologists." He said, "If this Society intends to work successfully on behalf of surgical oncologists, it must represent most of them." 15

Thus, this second quarter century in the Society's history included the seminal events of renaming and opening up membership to the broader surgical oncology community, as well as the creation and administration of formal training programs in surgical oncology. However, as the Society approached its 50th anniversary, it appeared to have at least lost its momentum and had ended at a low ebb. But the mission of the Society and the resolve of its leadership prevailed, and the SSO moved into a transformative period of growth in all its dimensions during the next 25 years, as described in the third and final segment of its 75-year history.

ACKNOWLEDGMENT The authors thank Ms. Karen Hurley and Kathy Sampson in the SSO Headquarters Office for their assistance in gathering materials, Drs. Walter Lawrence and Blake Cady for reviewing the manuscript, and Deborah Whippen for editorial assistance. We also thank Ms. Katherine Brennan at the MSKCC Archives, Rockefeller Archives Center, for her assistance in obtaining some of the original minutes of the James Ewing Society and photos. These documents were located in Record Group 520, James Ewing Society Papers. 


\section{SIDEBAR I: DEFINING THE FUNCTION OF A SURGICAL ONCOLOGIST FROM PAST PRESIDENTS (1965-1990)}

The surgical oncologist completing such a program (i.e., surgical oncology fellowship) could then truly participate in the interdisciplinary approach to cancer care. He would have achieved some basic knowledge and understanding of the problems and technique of radiation therapy and chemotherapy...As a teacher he can be an informant on the newer methods of diagnosis and treatment, and can stress to the other surgeons in the community the importance of the multidisciplinary approach (to cancer care). Robert Schweitzer, $1974^{10}$

At least one-half of being a surgical oncologist is being a good operating surgeon. A sound, basic, and prolonged training in general surgery is essential...The second half of the qualifications of a surgical oncologist is found in the fields of radiotherapy and chemoimmunotherapy. Edward Scanlon, $1975^{6}$

The oncologic surgeon is well trained in general surgery, then has overlying training in special oncologic surgery. He must be knowledgeable about radiation therapy, chemotherapy, and immunotherapy so that he is immediately aware of the advisability of multidisciplinary management of his patient... He should have 2 years of specialized training in oncology. Louis Guiss, $1976^{5}$

The surgical oncologist maintains daily contact with a surgical pathologist and has a major interest in the pathology and pathogenesis of neoplasms... He is familiar with currently known preventative measures and screening techniques. He is aware of the increasingly effective tools for early diagnosis and is an expert in the staging of cancer. He has the background and the skill to select and carry out the most appropriate surgical procedures for the definitive treatment of cancer as well as the many operations designed for effective palliation...He has the background and skill to participate in clinical or laboratory studies designed to improve our knowledge of cancer... While he is primarily a specialist in the surgical treatments of tumors, he maintains a working knowledge of radiation therapy...He is familiar with and often proficient in the use of many chemotherapeutic agents used in the management of cancer...In short, the surgical oncologist is an indispensable member of any multidisciplinary team organized for the study or treatment of cancer. Harvey Baker, $1978^{16}$

The oncologic surgeon must join with his colleagues in other disciplines. Failure to become a member of the therapeutic team initially will make it more difficult to join with that team in an effective way at a later time. LaSalle Leffall, $1979^{12}$

The surgical oncologist with research training and experience has an uncommon opportunity to carry out research in areas of particular interest to surgeons. Walter Lawrence, $1980^{9}$

The surgical oncologist, with his solid grounding in general surgery, is best suited to work out the sequential position of surgery in a multidisciplinary plan. Condict Moore, $1981^{17}$

A surgical oncologist should teach at the undergraduate or postgraduate level, play a leadership role in oncology in either the community hospital or in an academic institution, encourage or participate in basic or clinical oncological research, and foster interdisciplinary cooperation with other oncologic specialists...This surgeon possesses knowledge of current techniques and treatment by radiotherapy, chemotherapy, and immunotherapy. Robert McKenna, $1984^{18}$

To perform (cancer) surgery and then turn the case over to the medical oncologist converts us to mere technicians. Victor Dembrow, $1986^{19}$

\section{REFERENCES}

1. Leak GL. The James Ewing Society 1940-1968, presidential address. Cancer. 1966;19:1475.

2. Wilkins SA. Presidential address: the James Ewing Society 1940 1969. Cancer. 1970;25:322.

3. Lawrence W. The history of surgical oncology. In: Norton JA et al. (eds) Surgery: basic science and clinical evidence. New York: Springer; 2001.

4. Lawrence W. Some problems with clinical trials. James Ewing Lecture. Arch Surg. 1991;126:370-8.

5. Guiss LW. The surgical oncologist. Cancer. 1977;39:419.

6. Scanlon EF. Presidential address: the evolution of surgical oncology. Cancer. 1976;37:58-61.

7. Cady B. The Society of Surgical Oncology at a crossroads: thoughts for the future. Arch Surg. 1990;125:153-7.

8. Lawrence W. Is surgical oncology really a specialty? Arch Surg. 1979;114:659-61.

9. Lawrence W. Presidential address: the Society of Surgical Oncology: status of surgical oncology in the university. Cancer. $1981 ; 47: 2190-5$

10. Schweitzer RJ. Surgical oncology: the role of cancer control today. Cancer. 1975;35:592-5.

11. Schweitzer RJ, Edwards MH, Lawrence W, et al. Training guidelines for surgical oncology. Cancer. 1981;48:2336-40.

12. Leffall LD. Presidential address: surgical oncology: expectations for the future. Cancer. 1980;45:P2925-8.

13. Dembrow VD. Presidential address: the role of the surgical oncologist in the community hospital. Arch Surg. 1986;121:1231-2.

14. Lawrence W. Surgical oncology in university departments of surgery in the United States. Arch Surg. 1986;121:1088-93.

15. Rush BF. Wither, whether, or whither surgical oncology. Arch Surg. 1991;126:302.

16. Baker HW. Presidential address: the surgical treatment of cancer. Cancer. 1979;43:787-9.

17. Moore C. Presidential address: definition of an oncologist. Cancer. 1982;49:1067-9.

18. McKenna RJ. The privileges and responsibilities of the surgical oncologist. Cancer. 1985;55:1159-62.

19. Dembrow V. Presidential address. Arch Surg. 1986;121:1231-2. 